\title{
A Review of the Actions of D-cycloserine, a Putative Nootropic Agent, at the NMDA Receptor Complex-Associated Glycine Binding Site
}

\author{
$\underline{\text { J.W. Allen*, B.S. }}$
}

* To whom correspondence should be addressed: NW, Georgetown University Medical Center, 3900 Reservoir Road, Washington, D.C. 20007 USA

\section{INTRODUCTION}

Compounds that enhance the acquisition and retrieval of information, known broadly as nootropics, have long been sought. The development of nootropics has obvious clinical importance for the treatment of cognitive dysfunction associated with aging and pathological conditions such as Alzheimer's disease. Following the discovery of the $N$-methyl-D-aspartate (NMDA) glutamate receptor and its possible role in learning and memory, compounds acting at this receptor complex have been investigated for cognitionenhancing activity. One such compound is D-cycloserine (DCS), a broad-spectrum antibiotic currently administered at doses of 0.5 to 1.0 grams per day for the treatment of Mycobacterium tuberculosis infections $(1,2)$, which has been found to interact with the NMDA receptor complex (3).

This review will focus on the actions of DCS as mediated by the NMDA receptor complex, with emphasis placed upon the compound's possible nootropic activity. Following a brief discussion of the NMDA receptor, the interactions of DCS with this receptor will be presented, and studies investigating the use of DCS as a possible treatment for cognitive disorders will be reviewed.

\section{THE NMDA RECEPTOR COMPLEX}

The NMDA receptor complex is a voltage-dependent, ligand-gated ion channel with a high degree of calcium permeability, which has been postulated to exist as an heteromeric pentamer with a central ion-conducting pore (4-6). Even before this complex was discovered, its importance in learning and memory had been illustrated through a decrease in the severity of mental retardation in patients to whom glutamic acid was administered (7), and through a demonstrable increase in maze learning in rats with the use of NMDA agonists (8). After the discovery of long-term potentiation (LTP) (9)--a long-lasting increase in synaptic efficacy inducible in some areas of the CNS following tetanic stimulation, and a possible molecular mechanism in the biochemical cascade that leads to the formation of memories--it was demonstrated that the NMDA receptor complex was required for the induction of LTP in certain brain regions (10-13). Using a variety of techniques, including blockade with NMDA antagonists, investigators discovered that the activation of the NMDA receptor complex appeared to be involved in certain forms of learning and memory (14-17). 
Glutamate is an endogenous ligand for the NMDA receptor complex (18); however, it is now clear that glycine also interacts with this receptor. The co-administration of $3 \mu \mathrm{M}$ glycine and $300 \mu \mathrm{M}$ NMDA to Xenopus oocytes expressing the NMDA receptor elicits an increase in the maximum inward current over that seen with NMDA alone (19). Furthermore, the co-administration of these two compounds at similar concentrations to Xenopus oocytes expressing the NMDA receptor or to hippocampal neurons in vitro decreases the amount of apparent NMDA receptor desensitization that occurs with glutamate alone (19-21). In addition, NMDA has been found to increase the release of norepinephrine from rat hippocampal synaptosomes, which represent dissociated nerve terminals, and this release is enhanced by glycine and DCS, a glycine partial agonist (22). Using $\left[{ }^{3} \mathrm{H}\right]$ strychnine, a radiolabeled glycine antagonist, and $\left[{ }^{3} \mathrm{H}\right]$ glycine, it was demonstrated that two separate glycine-binding sites exist within the CNS: strychnine-sensitive (SS) sites, which have the highest density in the medulla, pons, and spinal cord; and strychnine-insensitive (SI) sites, which are found mainly within the cerebral cortex and cerebellum (23). The SS sites represent the glycine-coupled chloride ion channel, while the SI sites correlate with the glycine binding site associated with the NMDA receptor complex. This finding, coupled with the discovery of the NMDA receptor-associated glycine binding site (24), suggested that glycine may influence the activity of glutamate at the NMDA receptor complex.

Most investigators now agree that glycine is an absolute requirement for the activation of the NMDA receptor-associated cation channel, and it has been proposed that glycine and glutamate should be termed coagonists $(5,19,25-27)$. However, some investigators have suggested that glycine may be required to activate the NMDA receptor complex only under conditions of low glutamate concentrations $(28,29)$, although most of the current research does not appear to support this theory. Kinetic modeling and binding studies have indicated that the NMDA receptor complex contains two binding sites for glutamate and two for glycine (3033), and the glutamate and glycine binding sites are postulated to exist on the same protein (34). The exact nature of the interaction between these two ligands is unknown, as the reports of allosteric coupling are controversial and contradictory. Kinetic modeling of these interactions has suggested that the two ligands may show negative allosteric coupling $(5,30)$, whereas binding studies have indicated that glutamate increases the level of $\left[{ }^{3} \mathrm{H}\right]$ glycine binding (35-37) and glycine similarly increases the level of $\left[{ }^{3} \mathrm{H}\right]$ glutamate binding $(38,39)$. The latter studies suggest that glutamate and glycine exhibit positive allosteric coupling. Nonetheless, it is apparent that both glutamate and glycine binding is required for the activation of the NMDA receptor-associated cation channel.

Although the activation of the NMDA receptor complex requires the binding of both co-agonists, only glutamate, which exhibits the characteristics of transient release, has been described as a 'true' neurotransmitter, while glycine appears to be present continuously in the synaptic space (5). There is currently much debate concerning whether the levels of glycine in the CNS extracellular fluid (ECF) are sufficient to saturate the NMDA receptor-associated glycine binding sites. Because glycine is one of the most abundant amino acids in nature (it has been found in significant concentrations even in distilled water) (19), measurements of glycine in the ECF have been controversial (40). Direct measurements have found micromolar concentrations of glycine in the ECF, which is sufficient to saturate the SI glycine binding sites (41). In vivo studies utilizing rats have reported that the co-administration of NMDA and glycine agonists directly into the ventrobasal thalamus has only infrequently yielded small increases in NMDA receptor activation over that produced by NMDA alone (41). In vitro studies with brain slices have generally found no increase in the activation of the NMDA receptor complex $(25,42)$, or only small increases $(43)$, when an NMDA agonist is co-administered with glycine. These studies have led some investigators to hypothesize that the endogenous ECF glycine concentration may be enough to saturate the NMDA receptor complex in vivo (12).

However, saturation of the NMDA receptor-associated glycine binding sites, if it is a true phenomenon, may not occur in every brain microenvironment (44), such as that of the mossy fiber input to the cerebellar granule 
cells (45). The glycine concentration in the neonatal rat hippocampus has been suggested to be at subsaturating levels, as the administration of glycine facilitates the response of NMDA in the hippocampus of the neonatal rat, but not of the adult (44). Furthermore, the increase in cerebellar cyclic GMP, which occurs with the administration of NMDA agonists in vivo, has been shown to occur with the administration of glycine agonists (46-48), and glycine agonists have increased the seizure-inducing potency of NMDA agonists when they are co-administered (49). These data, along with the discovery of specific glycine transporters in the CNS (50), indicate that the levels of glycine in the ECF may not always exist at saturating concentrations, especially at the synaptic cleft (51). It has been suggested that in areas of high NMDA receptor density, such as the hippocampus, glycine may be differentially regulated by transporters so that glycine remains at subsaturating concentrations $(50,52)$.

Whether due to regional differences in ECF concentrations of glycine, or to regional differences in the subunits used to assemble the heteromeric NMDA receptor complex, both in vivo and in vitro studies suggest that glycine has site-specific characteristics within the CNS $(53,54)$. The increase in $\left[{ }^{3} \mathrm{H}\right]$ glutamate binding that occurs with glycine administration is dependent upon the area of the CNS under investigation, suggesting that regional heterogeneity exists for the glycine domain of the NMDA receptor complex $(39,55)$. The various pharmacological actions of NMDA antagonists also appear to be differentially modulated by glycine (56), which may be attributable to regional differences in glycine concentrations or to regional differences in the NMDA receptor complex.

In addition, the NMDA receptor complexes may not all be sensitive to glycine binding; for example, the coadministration of glycine with NMDA in the striatum elicits only a small increase in NMDA binding when compared with the administration of NMDA alone (29). Therefore, it is difficult to predict the actions of glycine agonists or antagonists upon a particular function, such as learning or memory, based solely on the expected activation or repression of the NMDA receptor complex.

Nonetheless, it is apparent that the regulation of the NMDA receptor complex by glycine is consistent in some regards, as glycine antagonists resemble NMDA antagonists in most respects (25). Like NMDA antagonists, glycine antagonists have been found to exhibit anticonvulsant (57-59), neuroprotective (60), and anxiolytic $(61,62)$ activities. Significant side effects of NMDA antagonists have been reported, including the induction of heat-shock proteins, some of which are markers of neuronal damage $(63,64)$. In contrast, glycine antagonists apparently have no significant toxicity, even at high doses (25). Similarly, whereas glycine agonists may only increase NMDA receptor function to the physiologic maximum, the NMDA agonists exhibit considerable toxicity (65-67), potentially inducing excessive stimulation and, ultimately, cell death (68). Glycine agonists and antagonists appear to have a greater safety margin than NMDA agonists and antagonists $(25,68,69)$, and therefore may prove to be more useful clinically $(65,70)$.

\section{D-CYCLOSERINE}

D-cycloserine (DCS) has been found to interact with the SI glycine binding site associated with the NMDA receptor complex $(3,71)$, and pharmacokinetic studies have indicated that DCS exhibits approximately 15fold less affinity for this glycine binding site than glycine (72,73). The intrinsic activity of DCS was estimated at $40 \%$ to $50 \%(3,74)$, although some reports have placed this value as high as $70 \%(66)$ or $86 \%$ (73). Regardless, DCS can be considered to act as a partial agonist at the NMDA receptor-associated glycine binding site $(3,28,47,66,73-75)$. The in vivo agonist actions of DCS at the NMDA receptor complex can be attributed to agonism of the glycine binding site, and not to an increase in glutamate release, as doses as high as

$320 \mathrm{mg} / \mathrm{kg}$ in rats and mice failed to induce any changes excitatory amino acid levels in the CNS (76).

DCS has been reported to have good oral bioavailability $(2,66)$, but the degree to which it crosses the bloodbrain barrier exhibits inter-species variability. It has been reported that only $17 \%$ to $20 \%$ of DCS crosses the blood-brain barrier in mice (56) and rats (76), while studies in humans have indicated that DCS freely crosses 
this barrier (2,77). The half-life of DCS in the mouse is approximately 23 minutes (78), indicating that the drug is rapidly cleared. DCS has a favorable toxicity profile $(66,77)$, and most studies report that even at high doses of up to $320 \mathrm{mg} / \mathrm{kg}$, the compound has no appreciable side effects in mice and rats (56,79-81).

However, various adverse reactions to DCS involving the CNS have been noted in humans. For example, DCS has been reported to induce tremor, dysarthria, psychotic states, paranoid reactions, catatonic reactions, clinical depression, hyperreflexia, and paresis (2). In addition, the drug is generally contraindicated in individuals with a history of epilepsy (2), as convulsions have been reported in some patients (82).

Studies with DCS have illustrated the myriad effects that can be pharmacologically manipulated by drugs acting at the NMDA receptor complex. DCS has been reported to decrease the pain response elicited by prolonged chemical noxious stimuli in mice (80), to enhance the development of rapid tolerance to ethanol in rats (83), and to act as a sociotropic (approach-promoting) agent in mice (84). Although DCS is a glycine partial agonist and, therefore, would be expected to exhibit either agonist or antagonist characteristics, depending upon the glycine concentration, it does not provide the same protection that NMDA antagonists exhibit against glutamate-induced neurotoxicity in cultured cerebellar granule neurons (85).

However, in a similar manner to the NMDA antagonists, DCS has been reported to have anxiolytic properties in rat and mouse anxiety models. Intraperitoneal injections of DCS at doses of $30-300 \mathrm{mg} / \mathrm{kg}$ block the fearpotentiated acoustic startle effect in rats, a model that is used to assess the anxiolytic activity of compounds (86). No anxiolytic effect was noted when the concentration of DCS was $10 \mathrm{mg} / \mathrm{kg}$, the lowest dose utilized in this study. Similarly, in a mouse punishment procedure, wherein mice are trained to avoid a darkened chamber with the use of a mild electric shock, DCS exhibited anxiolytic properties only at the dose of 1 $\mathrm{mg} / \mathrm{kg}$, and not at five times this dose (87). Although DCS acts as an anxiolytic in both models, the doseresponse curve generated is dependent upon the paradigm utilized and the neural pathways under investigation. This phenomenon is apparent in all of the pharmacological effects of DCS.

DCS acts as an anticonvulsant in certain animal models; however, this property only emerges at doses greater than $100 \mathrm{mg} / \mathrm{kg}$, which are generally higher than those required to exhibit its other properties $(76,88)$. DCS has been reported to have anticonvulsant activities against maximal electroshock seizures in rats $(56,71,81,89)$. In addition, DCS elicits almost complete suppression of kainate-induced seizures in rats (79), and antagonizes tonic convulsions induced by pentylenetetrazol (89). Some investigators have reported that DCS raises the seizure threshold in fully amygdala-kindled rats, wherein the amygdala was repeatedly stimulated so that an increased susceptibility to seizures was produced $(90,91)$. In contrast, others have suggested that DCS is ineffective in this model (89). DCS appears to have no antagonistic effects on convlusions induced by (S)-alpha-amino-3-hydroxy-5-methyl-4-isoxazolepropionic acid (92), clonic convulsions induced by pentylenetetrazol, electrically-induced nonkindled hippocampal seizures, or strychnine-induced tonic convulsions (89). Therefore, the anticonvulsant activity of DCS, in a similar manner to its anxiolytic properties, may be model and neural pathway dependent.

The administration of high doses of DCS, up to $320 \mathrm{mg} / \mathrm{kg}$, in naive mice does not have a proconvulsant effect (56), and DCS does not induce the paroxysmal activity in the limbic brain regions of kindled rats that has been seen with the administration of glycine antagonists and NMDA antagonists (93). In contrast, high doses of DCS in fully amygdala-kindled rats has been shown to be proconvulsant (91). Furthermore, DCS has been reported to act as a proconvulsant agent in humans, as it has induced tonic-clonic and absence seizures in susceptible individuals (2). These data indicate that DCS may act as an agonist in some animal models and as an antagonist in others. These findings may be related to the differential regulation of ECF glycine concentrations in the different micro-environments involved in each of these models; if the ECF glycine concentration at a particular synapse is enough to saturate the NMDA receptor-associated binding sites, then DCS could act as a glycine antagonist because of its lower intrinsic activity. However, if the ECF synaptic glycine concentration is at sub-saturating levels, then DCS may act as a glycine agonist. 
The cognitive-enhancing properties of NMDA agonists have been known for some time $(7,8)$ and, because of their interaction with the NMDA receptor complex, it has been speculated that glycine agonists would have similar properties. At the doses used in most of the studies of nootropic activity, DCS has no apparent effect upon the motivational state or the motor skills of experimental animals (94), suggesting that the actions of DCS in these studies are most likely due to specific effects on learning and memory. Although most of the research on the nootropic effects of DCS have utilized spatial memory tasks, DCS has been tested in other paradigms; for example, DCS was found to increase the response acquisition rate for rabbits in an eye-blink conditioning model (95).

In addition, the nootropic effects of DCS were examined in a punishment procedure involving a passive avoidance test. In this model, rats or mice are trained to avoid a chamber in which the animal had previously received an electric shock. To assess learning- or memory-enhancing properties of compounds, drugs are administered before or after the training, respectively, and the latency to enter the chamber on a subsequent trial is recorded. A study utilizing mice trained with a mild electric shock to avoid a darkened chamber found that DCS had no effect on learning when administered at a dose of $1 \mathrm{mg} / \mathrm{kg}$ or $5 \mathrm{mg} / \mathrm{kg}$ prior to training (87). However, the NMDA antagonists AP7 and MK-801 exhibited memoryimpairing activity in this model that was not seen with either dose of DCS (87), and may be a result of its intrinsic activity at the NMDA receptor complex. A separate study, in which rats were trained to avoid one of two chambers with the use of a mild electric shock, found DCS to be effective in increasing the latency time to enter a chamber at doses of $0.3-10 \mathrm{mg} / \mathrm{kg}$ (72). The difference between these two studies may be attributable to species differences in sensitivity to DCS, although this explanation is unlikely, as other paradigms that utilize mice have found increases in learning or memory with similar doses to those used in rats. Therefore, it is more likely that the paradigm that made use of the darkened chamber may not be sensitive enough to detect the subtle changes in cognition that may result from DCS administration.

Most investigators have found that DCS administration in rats and mice promoted spatial learning. Retention of a thirst-motivated linear maze task was enhanced by the administration of $10 \mathrm{mg} / \mathrm{kg}, 20 \mathrm{mg} / \mathrm{kg}$, or 80 $\mathrm{mg} / \mathrm{kg}$ of DCS to mice immediately following training (66). In addition, a dose of $3 \mathrm{mg} / \mathrm{kg}$ of DCS administered 20 minutes prior to training facilitated acquisition in this task. These data suggest that DCS may have effects on both spatial memory storage and retention. Weakly-trained mice injected with $20 \mathrm{mg} / \mathrm{kg}$ of DCS also exhibited greater retention of an electric shock-motivated T-maze task (96). However, this increase was not seen with doses of DCS less than $5 \mathrm{mg} / \mathrm{kg}$ or doses greater than $40 \mathrm{mg} / \mathrm{kg}$, indicating that although the two models--the thirst-motivated linear maze and the electric shock-motivated T-maze tasks--both test spatial learning and memory, each task is characterized by a distinct dose-response curve. Furthermore, a study utilizing rats in a food-motivated T-maze task found no increase in spatial learning with a DCS dose of $3 \mathrm{mg} / \mathrm{kg}$, but did find that this dose of DCS increased the acquisition of a reversal task in which rats were trained to enter one arm of the T-maze and subsequently trained to enter the other (72).

Because most of the available paradigms that measure changes in learning and memory may lack the sensitivity necessary to detect small increases or decreases in cognitive function in healthy animals, many investigators have utilized lesioned animals or pharmacologically-induced deficits in learning and memory to amplify the observable effects of nootropic compounds. Rats subjected to bilateral quinolinic acid-induced hippocampal lesions, which induce cell loss but do not completely destroy the hippocampus, exhibit working memory deficits that are reversible with the administration of $12 \mathrm{mg} / \mathrm{kg}$ of DCS prior to testing in a radial arm maze (97). Deficits in spatial memory, such as impairments in the water-maze or the T-maze paradigms, may also be induced by injections of scopolamine in healthy rats, which blocks the cholinergic input to the hippocampus that is required for its functioning in memory tasks (98). These deficits are reversible by the administration of doses of DCS ranging from $0.3-30 \mathrm{mg} / \mathrm{kg}(99,100)$. 
Scopolamine-induced learning and memory deficits have also been investigated in primates. Injections of $3-14 \mathrm{mg} / \mathrm{kg}$ of DCS given to rhesus monkeys failed to reverse a scopolamine-induced deficit of a spatial delayed response task; however, the highest dose of DCS administered, $14 \mathrm{mg} / \mathrm{kg}$, elicited slight improvements in particular tests (101). In contrast, elderly and young healthy human volunteers who received both scopolamine and DCS exhibited marked improvement in tasks of logic and verbal functions over that of volunteers who received scopolamine alone $(102,103)$. This data again illustrates that the dose-response curve and sensitivity of a particular task to DCS is dependent upon the function analyzed. For example, although most studies utilizing more than one dose of DCS found an inverted u-shaped dose-response curve for nootropic activity, each task and each species investigated exhibited a different optimal dose of DCS; this value ranged from a dose of $1 \mathrm{mg} / \mathrm{kg}$ for the reversal of scopolamine-induced deficits in rats (100) to 20 $\mathrm{mg} / \mathrm{kg}$ for the retention of a passive avoidance task in mice (96).

\section{THE USE OF D-CYCLOSERINE IN AGING AND COGNITIVE DISORDERS}

In the past, clinicians have attempted to use NMDA agonists to enhance cognitive function in conditions such as mental retardation (7), and recently focus has been placed upon the possible therapeutic benefit of glycine agonists. As noted above, the glycine agonists may exhibit a greater safety margin and, therefore, these compounds may be more beneficial for therapeutic administration than the NMDA agonists because of the possible toxicity of the latter $(25,65,68,70)$. Because aging is associated with decrements in learning and memory functions, some investigators have attempted to reverse these changes with glycine agonists. Aged rats exhibit decreases in the NMDA-induced release of norepinephrine from rat hippocampal synaptosomes, and DCS has been reported to increase this release, indicating a possible rationale for the use of DCS in the reversal of age-related changes (22). Furthermore, aged rats show impairments in the water-maze paradigm, and a $1 \mathrm{mg} / \mathrm{kg}$ dose of DCS was found to lessen the age difference between aged and young rats in both place discrimination and repeated acquisition tests (104). In addition, DCS has been reported to reverse the memory retention deficit associated with senescence-accelerated mice (96).

Some researchers and clinicians have advocated the investigation of DCS for the symptomatic treatment of Alzheimer's disease (AD), a neurodegenerative disease characterized clinically by learning and memory deficits $(1,105,106)$. Post-mortem AD brains exhibit a selective impairment in the coupling of the glycine binding site with the glutamate binding site of the NMDA receptor complex, as measured by the reduced amount of glycine-stimulated $\left[{ }^{3} \mathrm{H}\right] \mathrm{MK}-801$ binding in AD brains as compared with control brains (107). This finding may result from a decrease in the number of NMDA receptor complex-associated glycine binding sites, or in the sensitivity of these glycine binding sites. Therefore, the potential exists for clinical improvement in $\mathrm{AD}$ patients through the administration of glycine agonists. In a small pilot study of six patients with probable $\mathrm{AD}$, five patients exhibited improvements with a dose of either $5 \mathrm{mg} / \mathrm{kg} \mathrm{or} 15 \mathrm{mg} / \mathrm{kg}$ of DCS administered over a seven-day period (1). A much larger study, which employed 108 patients with probable $\mathrm{AD}$, found that $15 \mathrm{mg}$ of DCS administered twice daily significantly enhanced implicit learning and retention over a three-day period (108). In contrast, a similar study which included 12 patients with probable $\mathrm{AD}$, found no significant or consistent improvement in cognitive function (109). However, it is clear that these studies are too preliminary to reach a judgment on the clinical efficacy of DCS in the treatment of AD.

Because a functional interaction between the glutamatergic and dopaminergic pathways exists, the use of glycine agonists has been postulated as a treatment for schizophrenia, a disorder in which the underlying pathology has been attributed to an excessive stimulation of dopaminergic pathways (110). The increase in dopaminergic activity in schizophrenia may be related to a decrease in glutamatergic transmission (1), and this hypothesis has been corroborated by the low levels of glutamate found in the CSF of patients with schizophrenia (111). In addition, DCS was found to inhibit the hypermotility in rats induced by the administration of methamphetamine, which increases dopaminergic transmission. Similarly, DCS inhibited the behavioral responses elicited by selective stimulation of the D1 or D2 dopamine receptor subtypes (112). DCS was also reported in rats to enhance the neuroleptic activity of D1 and D2 receptor blockers (113), and 
to decrease both the number and function of these dopamine receptors, leading to a decrease in dopaminergic transmission (114). Therefore, DCS might be able to antagonize the effect of elevated dopamine levels seen in schizophrenic patients through the stimulation of the NMDA receptor complex.

However, DCS elicited little response when it was utilized in a mouse hyperactivity model of psychosis (115). Furthermore, in a clinical trial of seven patients with chronic schizophrenia who received $250 \mathrm{mg}$ of DCS as an adjuvant to conventional neuroleptics, only one patient exhibited a slight improvement (77). Interestingly, this patient was the only patient with the catatonic type of schizophrenia enrolled in the study. In contrast, a daily dose of $50 \mathrm{mg}$ of DCS significantly reduced the negative symptoms and significantly improved the reaction time of nine patients with chronic schizophrenia when combined with conventional neuroleptics (116). Therefore, DCS may still prove to be beneficial in the treatment of certain forms or of certain symptoms of schizophrenia, and further investigations are warranted. Similarly, glycine partial agonists and glycine antagonists may also be effective in the treatment of other disorders such as Parkinson's disease, in which the antagonism of glutamatergic transmission may lead to a reversal of the decreased activity of the dopaminergic pathways (70).

One investigator has envisioned the administration of low doses of glycine agonists for use in conditions of memory impairment without associated neuro- degeneration, and the use of high doses of these compounds in cognitive impairments with associated neurodegeneration, or in the aging brain (106). It has been suggested that the efficacy of DCS may be attributed to the relief of excessive glutamate antagonism from kynurenic acid, an endogenous glutamate receptor antagonist whose levels have been shown to increase in conditions associated with cognitive deficits (117). Furthermore, some pathological conditions may be related to the dysfunction of the glycine transporter, for which glycine partial agonists could be useful in antagonizing the saturation of the NMDA receptor-associated glycine binding site, without the complete antagonism seen with glycine antagonists.

However, the clinical efficacy of compounds such as DCS is questionable, as chronic exposure to these drugs has frequently led to desensitization. A dose of $3 \mathrm{mg} / \mathrm{kg}$ of DCS, which had previously been reported to facilitate the retention of a thirst-motivated linear-maze task with acute post-training injections, failed to exhibit an increase in retention when administered to mice for 15 days, with a subsequent acute post-training injection (66). The desensitization seen in this experiment was postulated by the investigators to be produced by a nitric oxide-induced downregulation of the NMDA receptor complex. This scenario is unlikely, however, because chronic exposure to DCS had no effect on the protection to glutamate neurotoxicity exhibited by NMDA antagonists, indicating that the receptor was still present after chronic DCS administration (85).

This author suggests that the NMDA receptor-associated glycine site may undergo selective desensitization, independent of the glutamate binding sites. Therefore, the glycine binding site may 'uncouple' from the rest of the NMDA receptor complex. This hypothesis is corroborated by the finding that while the NMDA antagonists retained efficacy in the culture system above, compounds that act at the glycine binding site exhibited reduced neuroprotection after chronic exposure to DCS (85). This uncoupling of the glycine binding site from the NMDA receptor-associated glutamate binding site superficially resembles the state of the NMDA receptor complex in AD, in which the efficacy of glycine at this binding site is also reduced (107). Therefore, it is conceivable that some of the pathology in AD may be related to excessive stimulation of the NMDA receptor-associated glycine binding site, which could result from dysfunctional ECF glycine regulation. However, this hypothesis needs to be examined in further detail.

\section{CONCLUSION}

The nootropic effect of DCS in rats and mice for certain tasks appears to be well-established, although each task analyzed has revealed a different optimal dose. However, the nootropic properties of DCS have not been consistently seen in human and non-human primate models. The lack of response to DCS in these studies 
may reflect the shifting dose-response curve that is found in the rat and mouse studies. Therefore, subsequent studies in humans and non-human primates will need to examine multiple doses of DCS before a conclusion can be drawn about the nootropic efficacy of this compound. The optimal dose of DCS for particular tasks has been found to be as low as $1 \mathrm{mg} / \mathrm{kg}$ in rats (100), and the CNS concentrations of DCS in rats at this dose may be as low as $0.2 \mathrm{mg} / \mathrm{kg}$. Similarly, the studies in humans reporting that DCS enhanced learning and memory utilized a CNS concentration of DCS of approximately $0.2 \mathrm{mg} / \mathrm{kg}$ (estimated for a $70 \mathrm{~kg}$ individual with free access of the drug across the blood-brain barrier) $(1,102)$. In contrast, studies suggesting that DCS has no nootropic activity in humans and non-human primates utilized a dose of DCS that was at least twice this concentration $(101,109)$.

Although further investigations into the actions of DCS are required, especially those that utilize humans and non-human primates, this compound holds promise for the symptomatic treatment of disorders such as Alzheimer's disease, schizophrenia, Parkinson's disease, and the cognitive dysfunction associated with aging. Furthermore, the issue of DCS-induced desensitization of the NMDA receptor-associated glycine binding site needs to be addressed before DCS can be considered as a potential therapeutic for these chronic disorders.

\section{REFERENCES}

1. Fonnum F, Myhrer T, Paulsen RE, et al. Role of glutamate and glutamate receptors in memory function and Alzheimer's disease. Annals of the New York Academy of Sciences 757: 475-486; 1995.

2. Mandell GL, Sande MA. Antimicrobial agents. In: Gilman AG, Rall TW, Nies AS, Taylor P, eds. Goodman and Gilman's the pharmacological basis of therapeutics. 8th edition. New York: McGraw-Hill, Inc.; 1990.

3. Hood WF, Compton RP, Monahan JB. D-cycloserine: a ligand for the $N$-methyl-D-aspartate coupled glycine receptor has partial agonist characteristics. Neuroscience Letters 98(1): 91-95; 1989.

4. Kutsuwada T, Kashiwabuchi N, Mori H, et al. Molecular diversity of the NMDA receptor channel. Nature 358(6381):36-41; 1992.

5. McBain CJ, Mayer ML. N-methyl-D-aspartic acid receptor structure and function. Physiological Reviews 74(3): 723-760; 1994.

6. Meguro H, Mori H, Araki K, et al. Functional characterization of a heteromeric NMDA receptor channel expressed from cloned cDNAs. Nature 357(6373): 70-74; 1992.

7. Vogel W, Broverman DM, Draguns JG. The role of glutamic acid in cognitive behaviors. Psychology Bulletin 65(6): 367-382; 1966.

8. Zimmerman GT, Ross S. Effect of glutamic acid and other amino acids on maze learning in the rat. Archives of Neurology and Psychiatry 51: 446-451; 1944.

9. Bliss TV, Lomo T. Long-lasting potentiation of synaptic transmission in the dentate area of the anaesthetized rabbit following stimulation of the perforant path. Journal of Physiology (London) 232(2): 331$356 ; 1973$.

10. Artola A, Singer W. Long term potentiation and NMDA receptors in rat visual cortex. Nature 330(6149): 649-652; 1987.

11. Collingridge GL, Kehl SH, McLennan H. Excitatory amino acids in synaptic transmission in the Schaffer collateral-commissural pathway of the rat hippocampus. Journal of Physiology 334: 33-46; 1983. 
12. Gozlan H, Khazipov R, Ben-Ari Y. Multiple forms of long-term potentiation and multiple regulatory sites of $N$-methyl-D-aspartate receptors: role of the redox site. Journal of Neurobiology 26(3): 360-369; 1995.

13. Harris EW, Ganong AH, Cotman CW. Long-term potentiation in the hippocampus involves activation of $N$-methyl-D-aspartate receptors. Brain Research 323(1): 132-137; 1984.

14. Bliss TV, Collingridge GL. A synaptic model of memory: long-term potentiation in the hippocampus. Nature 361(6407): 31-39; 1993.

15. Heale V, Harley C. MK-801 and AP-5 impair acquisition, but not retention, of the Morris milk maze. Pharmacology, Biochemistry, and Behavior 36(1): 145-149; 1990.

16. Malenfant SA, O'Hearn S, Fleming AS. MK-801, an NMDA antagonist, blocks acquisition of a spatial task but does not block maternal experience effects. Physiology and Behavior 49(6): 1129-1137; 1991.

17. Morris RGM, Anderson E, Lynch GS, et al. Selective impairment of learning and blockade of long-term potentiation by an $N$-methyl-D-aspartate receptor antagonist, AP5. Nature 319(6056): 774-776; 1986.

18. Watkins JC, Evans RH. Excitatory amino acid transmitters. Annual Review of Pharmacology and Toxicology 21: 165-204; 1981.

19. Dingledine R, Kleckner NW, McBain CJ. The glycine coagonist site of the NMDA receptor. Advances in Experimental Medicine and Biology 268: 17-26; 1990.

20. Mayer ML, Vyklicky L Jr, Clements J. Regulation of NMDA receptor desensitization in mouse hippocampal neurons by glycine. Nature 338(6214): 425-427; 1989.

21. Vyklicky L Jr, Benveniste M, Mayer ML. Modulation of $N$-methyl-D-aspartic acid receptor desensitization by glycine in mouse cultured hippocampal neurones. Journal of Physiology 428: 313-331; 1990.

22. Pittaluga A, Fedele E, Risiglione C, et al. Age-related decrease of the NMDA receptor-mediated noradrenaline release in rat hippocampus and partial restoration by D-cycloserine. European Journal of Pharmacology 231(1): 129-134; 1993.

23. Bristow DR, Bowery NG, Woodruff GN. Light microscopic autoradiographic localization of $\left[{ }^{3} \mathrm{H}\right] \mathrm{glycine}$ and $\left[{ }^{3} \mathrm{H}\right]$ strychnine binding sites in rat brain. European Journal of Pharmacology 126(3): 303-307; 1986.

24. Johnson JW, Ascher P. Glycine potentiates the NMDA response in cultured mouse brain neurons. Nature 325(6104): 529-531; 1987.

25. Kemp JA, Leeson PD. The glycine site of the NMDA receptorfive years on. Trends in Pharmacological Sciences 14(1): 20-25; 1993.

26. Kleckner NW, Dingledine R. Requirement for glycine in activation of NMDA-receptors expressed in Xenopus oocytes. Science 241(4867): 835-837; 1988.

27. Lehmann J, Colpaert F, Canton H. Glutamate and glycine co-activate while polyamines merely modulate the NMDA receptor complex. Progress in Neuropsychopharmacology and Biological Psychiatry 15(2):183$190 ; 1991$.

28. Hood WF, Compton RP, Monahan JB. N-methyl-D-aspartate recognition site ligands modulate activity at 
the glycine recognition site. Journal of Neurochemistry 54(3): 1040-1046; 1990.

29. Layer RT, Bland LR, Skolnick P. MK-801, but not drugs acting at strychnine-insensitive glycine receptors, attenuate methamphetamine nigrostriatal toxicity. Brain Research 625(1): 38-44; 1993.

30. Benveniste MJ, Clements L, Vyklicky L, et al. A kinetic analysis of the modulation of $N$-methyl-Daspartic acid receptors by glycine in mouse cultured hippocampal neurones. Journal of Physiology (London) 428: 333-357; 1990.

31. Benveniste M, Mayer ML. Kinetic analysis of antagonist action at $N$-methyl-D-aspartatic acid receptors. Two binding sites each for glutamate and glycine. Biophysical Journal 59(3): 560-573; 1991.

32. Clements JD, Westbrook GL. Activation kinetics reveal the number of glutamate and glycine binding sites on the $N$-methyl-D-aspartate receptor. Neuron 7(4): 605-613; 1991.

33. Patneau DK, Mayer ML. Structure-activity relationships for amino acid transmitter candidates acting at $N$-methyl-D-aspartate and quisqualate receptors. Journal of Neuroscience 10(7): 2385-2399; 1990.

34. Moriyoshi K, Masu M, Ishii T, et al. Molecular cloning and characterization of the rat NMDA receptor. Nature 354(6348): 31-37; 1991.

35. Kessler M, Terramani T, Lynch G, et al. A glycine site associated with $N$-methyl-D-aspartic acid receptors: characterization and identification of a new class of antagonists. Journal of Neurochemistry 52(4): 1319-1328; 1989.

36. Monahan JB, Biesterfeldt JP, Hood WF, et al. Differential modulation of the associated glycine recognition site by competitive $N$-methyl-D-aspartate receptor antagonists. Molecular Pharmacology 37(6): 780-784; 1990.

37. Ransom RW, Deschenes NL. Polyamines regulate glycine interaction with the $N$-methyl-D-aspartate receptor. Synapse 5(4): 294-298; 1990.

38. Fadda E, Danysz W, Wroblewski JT, et al. Glycine and D-serine increase the affinity of $N$-methyl-Daspartate sensitive glutamate binding sites in rat brain synaptic membranes. Neuropharmacology 27(11): $1183-1185 ; 1988$.

39. Monaghan DT, Olverman HJ, Nguyen L, et al. Two classes of $N$-methyl-D-aspartate recognition sites: differential distribution and differential regulation by glycine. Proceedings of the National Academy of Sciences (USA) 85(24): 9836-9840; 1988.

40. Ascher P. Measuring and controlling the extracellular glycine concentration at the NMDA receptor level. Advances in Experimental Medicine and Biology 268: 13-16; 1990.

41. Salt TE. Modulation of NMDA receptor-mediated responses by glycine and D-serine in the rat thalamus in vivo. Brain Research 481(2): 403-406; 1989.

42. Fletcher EJ, Lodge D. Glycine reverses antagonism of $N$-methyl-D-aspartate (NMDA) by 1-hydoxy-3aminopyrrolidone-2 (HA-966) but not by D-2-amino-5-phosphonovalerate (D-AP5) on rat cortical slices. European Journal of Pharmacology 151(1): 161-162; 1988.

43. Thomson AM, Walker VE, Flynn DM. Glycine enhances NMDA-receptor mediated synaptic potentials in neocortical slices. Nature 338(6214): 422-424; 1989. 
44. Gaiarsa JL, Corradetti R, Cherubini E, et al. The allosteric glycine site of the $N$-methyl-D-aspartate receptor modulates GABAergic-mediated synaptic events in neonatal rat CA3 hippocampal neurons. Proceedings of the National Academy of Sciences (USA) 87(1): 343-346; 1990.

45. D'Angelo E, Rossi P, Garthwaite J. Dual-component NMDA receptor currents at a single central synapse. Nature 346(6283): 467-470; 1990.

46. Danysz W, Wroblewski JT, Brooker G, et al. Modulation of glutamate receptors by phencyclidine and glycine in the rat cerebellum: cGMP increase in vivo. Brain Research 479(2): 270-276; 1989.

47. Emmett MR, Mick SJ, Cler JA, et al. Actions of D-cycloserine at the $N$-methyl-D-aspartate-associated glycine receptor site in vivo. Neuropharmacology 27: 1183-1185; 1991.

48. Wood PL, Emmett MR, Rao TS, et al. In vivo modulation of the $N$-methyl-D-aspartate receptor complex by D-serine: potentiation of ongoing neuronal activity as evidenced by increased cerebellar cyclic GMP. Journal of Neurochemistry 53(3): 979-981; 1989.

49. Singh L, Oles RJ, Tricklebank MD. Modulation of seizure susceptibility in the mouse by the strychnineinsensitive glycine recognition site of the NMDA receptor/ion channel complex. British Journal of Pharmacology 99(2): 285-288; 1990.

50. Smith KE, Borden LA, Hartig PR, et al. Cloning and expression of a glycine transporter reveal colocalization with NMDA receptors. Neuron 8(5): 927-935; 1992.

51. Gu Y, Huang L-YM. Modulation of glycine affinity for NMDA receptors by extracellular $\mathrm{Ca}^{2+}$ in trigeminal neurons. Journal of Neuroscience 14(7): 4561-4570; 1994.

52. Pitkanen M, Sirvio J, Lahtinen H, et al. D-cycloserine, a partial agonist at the glycine site, enhances the excitability of dentate granule cells in vivo in rats. European Journal of Pharmacology 253(1-2): 125-129; 1994.

53. Yoneda Y, Ogita K. Heterogeneity of the $N$-methyl-D-aspartate receptor ionophore complex in rat brain, as revealed by ligand binding techniques. Journal of Pharmacological Experimental Therapeutics 259(1): 86$96 ; 1991$.

54. Lehman JC, Procureur D, Wood PL. 7-chlorokynurenate prevents NMDA-induced and kainate-induced striatal lesions. Brain Research 620(1): 1-6; 1993.

55. O'Shea RD, Manallack DT, Conway EL, et al. Evidence for heterogenous glycine domains but conserved multiple states of the excitatory amino acid recognition site of the NMDA receptor: regional binding studies with $\left[{ }^{3} \mathrm{H}\right]$ glycine and $\left[{ }^{3} \mathrm{H}\right] \mathrm{L}-$ glutamate. Experimental Brain Research 86(3): 652-662; 1991.

56. Wlaz P, Baran H, Loscher W. Effect of the glycine/NMDA receptor partial agonist, D-cycloserine, on seizure threshold and some pharmacodynamic effects of MK-801 in mice. European Journal of Pharmacology 257(3): 217-225; 1994.

57. Croucher MJ, Bradford HF. The influence of strychnine-insensitive glycine receptor agonists and antagonists on generalized seizure thresholds. Brain Research 543(1): 91-96; 1991.

58. Koek W, Colpaert FC. Selective blockade of $N$-methyl-D-aspartate (NMDA)-induced convulsions by NMDA antagonists and putative glycine antagonists: relationship with phencyclidine-like behavioral effects. Journal of Pharmacology and Experimental Therapeutics 252(1): 349-357; 1990. 
59. Singh L, Donald AE, Foster AC, et al. Enantiomers of HA-966 (3-amino-1-hydroxypyrrolid-2-one) exhibit distinct central nervous system effects: (+)-HA-966 is a selective glycine/ $N$-methyl-D-aspartate receptor antagonist, but (-)-HA-966 is a potent gamma-butyrolactone-like sedative. Proceedings of the National Academy of Sciences (USA) 87(1): 347-351; 1990.

60. Priestley T, Horne AL, McKernan RM, et al. The effect of NMDA receptor glycine site antagonists on hypoxia-induced neurodegeneration of rat cortical cell cultures. Brain Research 531(1-2): 183-188; 1990.

61. Dunn RW, Flanagan DM, Martin LL, et al. Stereoselective R-(+) enantiomer of HA-966 displays anxiolytic effects in rodents. European Journal of Pharmacology 214: 207-214; 1992.

62. Kehne JH, McCloskey TC, Baron BM, et al. NMDA receptor complex antagonists have potential anxiolytic effects as measured with separation-induced ultrasonic vocalizations. European Journal of Pharmacology 193(2): 283-292; 1991.

63. Olney JW, Labruyere J, Price MT. Pathological changes induced in cerebrocortical neurons by phencyclidine and related drugs. Science 244(4910): 1360-1362; 1989.

64. Olney JW, Labruyere J, Wang G, et al. NMDA antagonist neurotoxicity: mechanism and prevention. Science 254(5037): 1515-1518; 1991.

65. Bowen, DM. Treatment of Alzheimer's disease. Molecular pathology versus neurotransmitter-based therapy. British Journal of Psychiatry 157: 327-330; 1990.

66. Quatermain D, Mower J, Rafferty MF, et al. Acute but not chronic activation of the NMDA-coupled glycine receptor with D-cycloserine facilitates learning and retention. European Journal of Pharmacology 257(1-2): 7-12; 1994.

67. Rupniak NM, Duchnowski M, Tye SJ, et al. Failure of D-cycloserine to reverse cognitive disruption induced by scopolamine or phencyclidine in primates. Life Sciences 50(25): 1959-1962; 1992.

68. Muller WE, Scheuer K, Stoll S. Glutamatergic treatment strategies for age-related memory disorders. Life Sciences 55(25-26): 2147-2153; 1994.

69. Berger P, Farrel K, Sharp F, et al. Drugs acting at the strychnine-insensitive glycine receptor do not induce HSP-70 protein in the cingulate cortex. Neuroscience Letters 168(1-2): 147-150; 1994.

70. Carlsson M, Carlsson A. Interaction between glutamatergic and monoaminergic systems within the basal ganglia--implications for schizophrenia and Parkinson's disease. Trends in Neuroscience 13(7): 272-276; 1990.

71. Peterson SL. Localization of an anatomic substrate for the anticonvulsant activity induced by Dcycloserine. Epilepsia 35(5): 933-938; 1994.

72. Monahan JB, Handelmann GE, Hood WF, et al. D-cycloserine, a positive modulator of the $N$-methyl-Daspartate receptor, enhances performance of learning tasks in rats. Pharmacology, Biochemistry, and Behavior 34(3): 649-653; 1989.

73. Priestley T, Kemp JA. Kinetic study of the interactions between the glutamate and glycine recognition sites on the $N$-methyl-D-aspartic acid receptor complex. Molecular Pharmacology 46(6): 1191-1196; 1994.

74. Watson GB, Bolanowski MA, Baganoff MP, et al. D-cycloserine acts as a partial agonist at the glycine 
modulatory site of the NMDA receptor expressed in Xenopus oocytes. Brain Research 510(1): 158-160; 1990.

75. Henderson G, Johnson JW, Ascher P. Competitive antagonists and partial agonists at the glycine modulatory site of the mouse $N$-methyl-D-aspartate receptor. Journal of Physiology (London) 430: 189-212; 1990.

76. Baran H, Gramer M, Loscher W. Alterations in plasma and brain amino acids after administration of the glycine/NMDA receptor partial agonist, D-cycloserine, to mice and rats. European Journal of Pharmacology 273(1-2): 197-201; 1995.

77. Cascella NG, Macciardi F, Cavallini C, et al. D-cycloserine adjuvant therapy to conventional neuroleptic treatment in schizophrenia: an open-label study. Journal of Neural TransmissionGeneral Section 95(2): 105$111 ; 1994$.

78. Conzelman GM Jr, Jones RK. On physiological disposition of cycloserine in experimental animals. The American Review of Tuberculosis and Pulmonary Diseases 74: 802-806; 1956.

79. Baran H, Loscher W, Mevissen M. The glycine/NMDA receptor partial agonist D-cycloserine blocks kainate-induced seizures in rats. Comparison with MK-801 and diazepam. Brain Research 652(2): 195-200; 1994.

80. Millan MJ, Seguin L. Chemically-diverse ligands at the glycine B site coupled to $N$-methyl-D-aspartate (NMDA) receptors selectively block the late phase of formalin-induced pain in mice. Neuroscience Letters 178(1): 139-143; 1994.

81. Peterson SL. 7-Chlorokynurenic acid antagonizes the anticonvulsant activity of D-cycloserine in maximal electroshock seizures. Epilepsy Research 13(1): 73-81; 1992.

82. Storey PB, McLean R1. A current appraisal of cycloserine. Antibiotic Medicine and Clinical Threapy 4: 223-232; 1957.

83. Khanna JM, Kalant H, Shah G, et al. Effect of D-cycloserine on rapid tolerance to ethanol. Pharmacology, Biochemistry, and Behavior 45(4): 983-986; 1993.

84. McAllister KH. D-cycloserine enhances social behaviour in individually-housed mice in the residentintruder test. Psychopharmacology 116(3): 317-325; 1994.

85. Boje KM, Wong G, Skolnick P. Desensitization of the NMDA receptor complex by glycinergic ligands in cerebellar granule cell cultures. Brain Research 603(2): 207-214; 1993.

86. Anthony EW, Nevins ME. Anxiolytic-like effects of $N$-methyl-D-aspartate-associated glycine receptor ligands in the rat potentiated startle test. European Journal of Pharmacology 250(2): 317-324; 1993.

87. Faiman CP, Viu E, Skolnick P, et al. Differential effects of compounds that act at strychnine-insensitive glycine receptors in a punishment procedure. Journal of Pharmacology and Experimental Therapeutics 270(2): 528-533; 1994.

88. Norris DO, Mastropaolo J, O'Connor DA, et al. A glycinergic intervention potentiates the antiseizure efficacies of MK-801, flurazepam, and carbamazepine. Neurochemistry Research 19(2): 161-165; 1994.

89. Peterson SL, Schwade ND. The anticonvulsant activity of D-cycloserine is specific for tonic convulsions. Epilepsy Research 15(2): 141-148; 1993. 
90. Loscher W, Wlaz P, Rundfeldt C, et al. Anticonvulsant effects of the glycine/NMDA receptor ligands Dcycloserine and D-serine but not R-(+)-HA-966 in amygdala-kindled rats. British Journal of Pharmacology 112(1): 97-106; 1994.

91. Runfeldt C, Wlaz P, Loscher W. Anticonvulsant activity of antagonists and partial agonists for the NMDA receptor-associated glycine site in the kindling model of epilepsy. Brain Research 653(1-2): 125-130; 1994.

92. Bisaga A, Krzascik P, Jankowski E, et al. Effect of glutamate receptor antagonists on $N$-methyl-Daspartate- and (S)-alpha-amino-3-hydroxy-5-methyl-4-isoxazolepropionic acid-induced convulsant effects in mice and rats. European Journal of Pharmacology 242(3): 213-220; 1993.

93. Wlaz P, Ebert U, Loscher W. Low doses of the glycine/NMDA receptor antagonist R-(+)-HA-966 but not D-cycloserine induce paroxysmal activity in limbic brain regions of kindled rats. European Journal of Neuroscience 6(11): 1710-1719; 1994.

94. Herberg LJ, Rose IC. Effects of D-cycloserine and cycloleucine, ligands for the NMDA-associated strychnine-insensitive glycine site, on brain-stimulation reward and spontaneous locomotion. Pharmacology, Biochemistry, and Behavior 36(4): 735-738; 1990.

95. Thompson LT, Moskal JR, Disterhoft JF. Hippocampus-dependent learning facilitated with a monoclonal antibody or D-cycloserine. Nature 359(6396): 638-641; 1992.

96. Flood JF, Morley JE, Lanthorn TH. Effect on memory processing by D-cycloserine, an agonist of the NMDA/glycine receptor. European Journal of Pharmacology 221(2-3): 249-254; 1992.

97. Schuster GM, Schmidt WJ. D-cycloserine reverses the working memory impairment of hippocampallesioned rats in a spatial learning task. European Journal of Pharmacology 224(1): 97-98; 1992.

98. Olton DS, Givens BS, Markowska AM, et al. Mnemonic functions of the cholinergic septohippocampal system. In: Squire LR, Weinberger NM, Lynch G, McGaugh JL, editors. Memory: organization and locus of change. New York: Oxford, 1992.

99. Fishkin RJ, Ince ES, Carlezon WA Jr, et al. D-cycloserine attenuates scopolamine-induced learning and memory deficits in rats. Behavioral Neural Biology 59(2): 150-157; 1993.

100. Sirvio J, Ekonsalo T, Riekkinen P Jr, et al. D-cycloserine, a modulator of the $N$-methyl-D-aspartate receptor, improves spatial learning in rats treated with muscarinic antagonist. Neuroscience Letters 146(2): 215-218; 1992.

101. Chessell IP, Procter AW, Francis PT, et al. D-cycloserine, a putative cognitive enhancer, facilitates activation of the $N$-methyl-D-aspartate receptor-ionophore complex in Alzheimer brain. Brain Research 565(2): 345-348; 1991.

102. Jones RW, Wesnes KA, Kirby J. Effects of NMDA modulation in scopolamine dementia. Annals of the New York Academy of Sciences 640: 241-244; 1991.

103. Wesnes K, Jones RW, Kirby J. The effects of D-cycloserine, a glycine agonist, in a human model of the cognitive deficits associated with ageing and dementia. British Journal of Clinical Pharmacology 31: 577P578P; 1991.

104. Baxter MG, Lanthorn TH, Frick KM, et al. D-cycloserine, a novel cognitive enhancer, improves spatial memory in aged rats. Neurobiology of Aging 15(2): 207-213; 1994. 
105. Bowen DM, Francis PT, Pangalos MN, et al. Treatment strategies for Alzheimer's disease. Lancet 339(8785): 132-133; 1992.

106. Vamvakides A. Nootropic activity of glycinergic derivatives in relation to their dualistic effects on cerebral monoamines. Bollettino di Chimico Farmaceutico (Italy) 133(6): 369-373; 1994.

107. Procter AW, Wong EHG, Stratmann GC, et al. Reduced glycine stimulation of $\left[{ }^{3} \mathrm{H}\right] \mathrm{MK}-801$ binding in Alzheimer disease. Journal of Neurochemistry 53(3): 698-704; 1989.

108. Schwartz BL, Hashtroudi S, Herting RL, et al. D-cycloserine enhances implicit memory in Alzheimer patients. Neurology (In press).

109. Randolph C, Roberts JW, Tierney MC, et al. D-cycloserine treatment of Alzheimer disease. Alzheimer Disease and Associated Disorders 8(3): 198-205; 1994.

110. Deutsch SI, Mastropaolo J, Schwartz BL, et al. 'A glutamate hypothesis' of schizophrenia. Rationale for pharmacotherapy with glycine. Clinical Neuropharmacology 12(1): 1-13; 1989.

111. Kim JS, Kornhuber HH, Schmid-Burgk W, et al. Low cerebrospinal fluid glutamate in schizophrenia patients and a new hypothesis on schizophrenia. Neuroscience Letters 20(3): 379-382; 1980.

112. Dall'Olio R, Rimondini R, Gandolfi O. The NMDA positive modulator D-cycloserine inhibits dopaminemediated behaviors in the rat. Neuropharmacology 33: 55-59; 1994.

113. Dall'Olio R, Gandolfi O. The NMDA positive modulator D-cycloserine potentiates the neuroleptic activity of D1 and D2 dopamine receptor blockers in the rat. Psychopharmacology 110(1-2): 165-168; 1993.

114. Gandolfi O, Rimondini R, Dall'Olio R. D-cycloserine decreases both D1 and D2 dopamine receptors number and their function in rat brain. Pharmacology, Biochemistry, and Behavior 48(2): 351-356; 1994.

115. Carlsson ML, Engberg G, Carlsson A. Effects of

D-cycloserine and (+)-HA-966 on the locomotor stimulation induced by NMDA antagonists and clonidine in monoamine-depleted mice. Journal of Neural Transmission--General Section 95(3): 223-233; 1994.

116. Goff DC, Tsai G, Manoach DS, et al. Dose-finding trial of D-cycloserine added to neuroleptics for negative symptoms in schizophrenia. American Journal of Psychiatry 152(8): 1213-1215; 1995.

117. Pittaluga A, Pattarini R, Raiteri M. Putative cognition enhancers reverse kynurenic acid antagonism at hippocampal NMDA receptors. European Journal of Pharmacology 272(2-3): 203-209; 1995.

\section{BIOGRAPHY}

Jason W. Allen received a B.S. in Cellular and Molecular Biology from Tulane University (New Orleans, Louisiana, USA) in 1993. He is presently a third-year M.D./Ph.D. student at Georgetown University (Washington, D.C., USA) in the Interdisciplinary Program in Neuroscience. His research on D-cycloserine was conducted during his first year of graduate school at Georgetown University.

Copyright (C) 1996 by MJM 